\title{
Laboratory Management of the Internet based on the Technology of Internet of Things
}

\author{
Chunxia Jia \\ Weifang University of Science and Technology, Shouguang, Shandong, 262700 China
}

\begin{abstract}
Laboratory information management based on the technology of Internet of things technology is the development trend of digital and information technology education in our country and the inevitable choice. Through the further study of the current situation of laboratory management in colleges and universities and the characteristics of the Internet of things technology, this paper introduces the concept of Internet of things technology, history and current situation of the development. With the most representative IOT architecture and Ubiquitous ID IOT system as an example, analyzes the RFID technology, sensor network and detection technology, intelligent technology and characteristics of Nanometer technology. Analysis the technical foundation for the development of the campus Internet of things, and give the Internet of things technology in the application of the laboratory management technology.
\end{abstract}

Keywords-internet of things technologies; laboratory management technology; things architecture.

\section{INTRODUCTION}

The "Internet of things", refers to a variety of information sensing devices such as radio frequency identification (RFID) devices, infrared sensors, global positioning systems, laser scanners and other devices and the Internet combine to form a huge network. The aim is to make all items are connected to the network with, the system can automatically and in real time for object identification, location, tracking, monitoring and corresponding event is triggered. The "Internet of things" is a computer, Internet and mobile communications network in the world after the third wave of the information industry. The "Internet of things" concept appeared, eclipsing the previous conventional wisdom. The thinking of the past has always been a separate physical infrastructure and IT infrastructure: on the one hand, airports, roads, buildings, and on the other hand is a data center, personal computers, broadband and so on. In the "Internet of Things" era, reinforced concrete, the cable will be integrated with the chip, a unified broadband infrastructure, in this sense, the infrastructure is more like a new earth site, running on top of the world in its conduct, which including economic management, production run, social management and even personal life."Internet of Things" concept was proposed in 1999, and its definition is very simple: all the items are connected by radio frequency identification and other information sensing device and the internet, intelligent identification and management.That is to say, the Internet of things refers to all kinds of sensors and the existing Internet mutual cohesion of a new technology. It consists of perception layer, transport layer and application layer, as showed in fig.1.

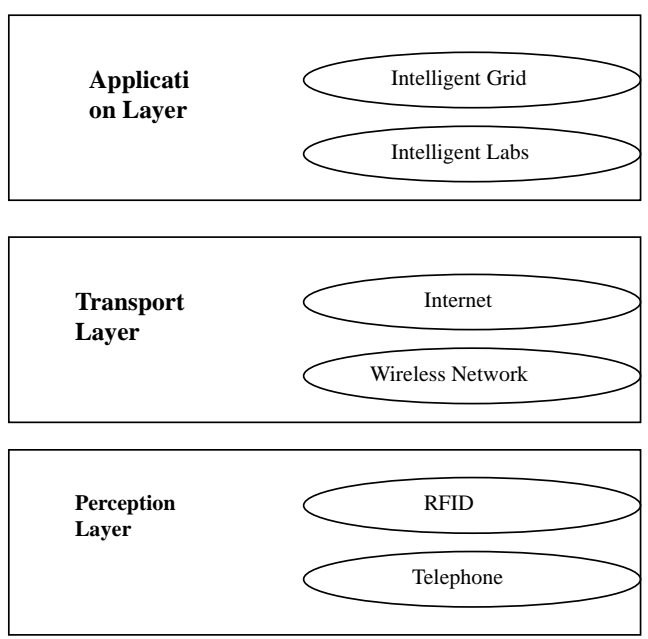

Figure 1. The hierarchical structure of the Internet of things

\section{THE CURRENT SITUATION OF LABORATORY MANAGEMENT AND THE INSUFFCIENCY}

At present, the test/calibration laboratory has been basically established internal office network, inspection information query system, GSM short message release system, security systems, access control and attendance system, instruments and equipment, electronic account, experiment sample electronic label management system basically realizes the informationization. But the information management system is aimed at a single, a transaction to laboratory experiments, field personnel, equipments, experiment samples for integrated information management, warehouse, etc. Lab access control and attendance system combined with foreign personnel management, testing/calibration laboratory personnel in addition to laboratory internal personnel, also includes the inspection factory personnel, the consultants, etc., according to the general requirements of testing and calibration laboratory capacity, the laboratory has nothing to do with the inspection personnel are not permitted to enter, outsiders or the customer enters the checkout room, must under the condition of the guarantee other client 
confidentiality, with the approval of the relevant departments, accompanied by the relevant personnel can enter below, does not allow outsiders were stuck in the detection place alone. But it's hard to put an end to the outside of the laboratory in site management personnel inadvertently into experimental sites, and even affect the normal test results of the experiment. Instrument equipment and sample management mostly adopts manual labeling, and then into the way of management, low efficiency, poor accuracy, this way can't dynamic management. About the Environment, such as temperature, humidity, lighting control have strict rules, now USES the manual control mode, basic control accuracy is poor, vulnerable to external disturbance is beyond control. Laboratory of lighting, power equipment, large equipment switch is unable to realize automatic adjustment, serious resource waste.

\section{INTERNET NETWORK SYSTEM AND SERVICE SYSTEM}

Currently, things have not a widely shared architecture, the most representative of Things architecture in Europe and America supported EPC Global "things" architecture and Japan Ubiquitous ID (UID) Things EPC global and Ubiquitous ID system in (Ubiquitous ID center) are international standardization organizations established to promote the standardization of RFID, China is also actively involved in the above-mentioned system of things, is actively developing in line with our development of the Internet of Things standards and architectures. EPC system encoded by the EPC system, the radio frequency identification system and information network system of three parts, including the six areas, as shown in Table 1. EPC "Things" architecture by the EPC code, EPC tags and readers, EPC middle-ware, ONS servers and EPCIS server and other parts.

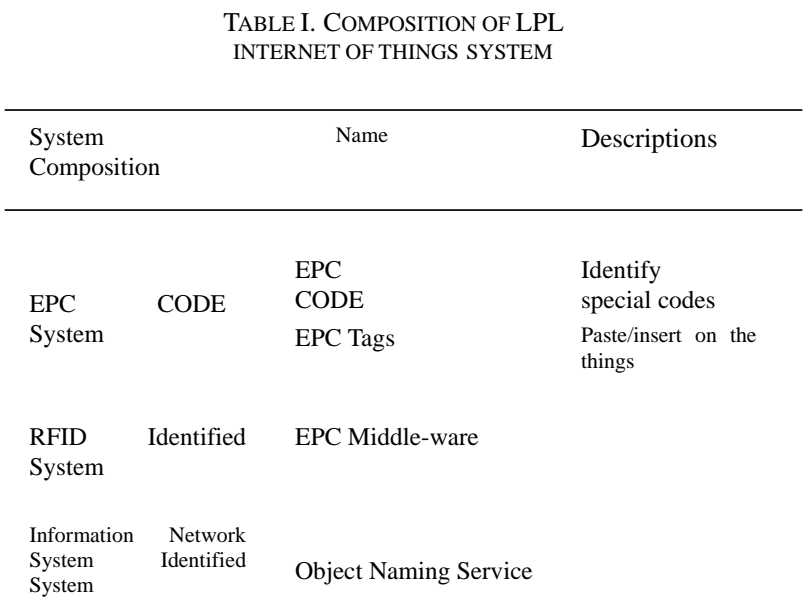

\section{KEY TECHNOLOGY FOR THE INTERNET OF THINGS}

ITU released a report entitled "Internet of Things", which is the first author Laura. Srivastava said: "We are standing at the entrance of a new communication era, in this era, the Internet as we know it will be a fundamental change in the Internet is a communication between the people's unprecedented. means, but now the Internet can help people connect with all the objects, but also the object and the object linking. "Things --RFID key technology to include the (radio frequency identification, radio frequency identification) radio frequency identification is a non-contact automatic identification technology that uses radio frequency signal through the automatic target recognition and access to relevant data, identification Process without human intervention, can work in a variety of harsh environments. RFID technology can identify fast moving objects and can also identify multiple tags, easy to operate. RFID technology and the Internet, telecommunications and other technology, can achieve asset tracking and information sharing worldwide. RFID (Radio Frequency Identification, radio frequency identification) is an electronic tag antenna and the IC package to a new type of passive electronic card plastic substrate; with data storage capacity, wireless passive, compact and lightweight, long life, waterproof, anti-magnetic security and safety features; in recent years developed a new type of product, the next few years to replace the bar code into the "Internet of Things" one of the key technologies of the times. Between the reader (i.e. PCE machine) and the electronic tag (i.e. PICC card) for energy, timing and data transmission via wireless electromagnetic induction.

\section{LAB CONSTRUCTION BASED ON INTERNET OF THINGS}

On the basis of the original internal LAN Settings in the lab data server, Web server, real-time communication server exports the background such as the network layer and the network system, increase the radio frequency identification (RFID), infrared sensors, global positioning system, laser scanner, state perception layer equipment such as sensors, new or modified environmental control, inspection, information query, GSM short message release, safety protection, access control and attendance, instruments and equipment status identification and control, application layer facilities such as the experimental sample state recognition. And through the system data integration, import the specific inspection procedures, documents flow control, etc., can be realized is the content of the laboratory, people, environment, experimental process and experimental process, the results of comprehensive management, as shown in fig.2. 


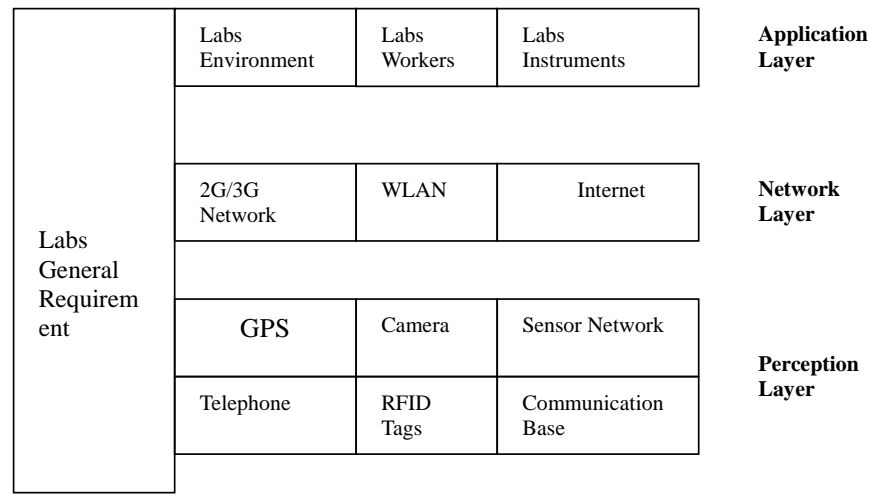

Figure 2. The labs structure of the Internet of things

\section{THE LABORATORY INFORMATION MANAGEMENT SYSTEM}

The basic framework of the campus Internet of things is mainly composed of campus network and its backend systems, application layer, sensor network and intelligent processing end user control terminals, etc. Internet information management center mainly relying on the existing technology more mature campus network, including its various servers and databases. Sensor network terminal through key authentication, data from card reader recognition, through wireless communication link and iot gateway transferred to the laboratory information management center. Users can control terminal through terminal equipment such as portable computers, mobile phones to obtain needed information. Intelligent processing can end in the first time to analyze the data from the sensor network in diagnosis, and send corresponding commands to control intelligent application terminals' the function of the laboratory information management center frame, it mainly includes the daily management, laboratory equipment, laboratory experiment teaching management. As long as through the relevant certification. The general teachers and students can enter the management system at any time by phone or computer, complete equipment to make an appointment.

\section{CONCLUSIONS}

Laboratory based on Internet of things intelligent management system design thought based on "people, machines, network, integrated interconnection, complementary advantages, intelligent interaction" for the purpose, to provide a user-oriented intelligent application, improve laboratory comprehensive management and service level as the goal, based on the Internet of things technology in ubiquitous Internet, real-time monitoring, dynamic display, intelligent control, flexible, interactive features such as application, finally realizes based on the preset "strategy" and "smart" lab entrance guard system, video surveillance, electric power, environmental protection, equipment operation and maintenance management system and the experiment site management information network, information and intelligence. As the system put into use, and constantly improve, the application of laboratory security, maintenance and management level and service quality can be effectively promoted.

\section{REFERENCES}

[1] Jin Wang. The lab management technology based on Internet of things [J]. Computer knowledge and technology, 2010, 21 (6) : 5741-5742.

[2] Baoyun Wang. Overview of IOT technology research[J].Journal of electronic measurement and instrument,2009,23(12),1-7.

[3] Quanti Sun,Yanbiao Li,Junjie Tian,et al.Of the construction of the laboratory of intelligent management system based on Internet of things [J]. Journal of course education research, 2014235-236.

[4] Yuechun Zhou,Ziqi Yan.Intelligent laboratory architecture research based on the technology of Internet of things [J]. Journal of laboratory research and exploration. 2014 (5) : 239-243.

[5] Sheng Ni. Design and Implementation of Web Based Lab Teaching Information Management System[J]. Research and Exploration in Laboratory, 2011, 30(1): 160-163.

[6] Xiuying Sun,Jie Li,Yanxia Yan, et a1. Construction and Application of Security Defense System of Laboratory[J]. China Modem Education Equipment, 2009(3): 114-115.

[7] Zhongbo Wei, Xuan Shen, Daping Pei. Safety Management of Key Laboratories in Universities[J]. Research and Exploration in Laboratory, 2013, 32(3): 246-248. 